\title{
Perceptions and Preference of Contemporary Teaching Methods among University Students of Pakistan- A Cross-Sectional Survey
}

\author{
Atif Mahmood ${ }^{1}$, Fahmida Khatoon ${ }^{2}$, Mukkaram $\mathrm{Ali}^{3}$, Saima Ejaz ${ }^{4}$, \\ Masood Anwar Qureshi ${ }^{5}$ \\ ${ }^{I}$ Department of Physiology, Shaheed Mohtarma Benazir Bhutto Medical College, Karachi, Pakistan. \\ ${ }^{2}$ Department of Biochemistry, United Medical and Dental College, Karachi, Pakistan. \\ ${ }^{3}$ Department of Forensic Medicine, Dow International Medical College, Dow University of Health Sciences, \\ Karachi, Pakistan. \\ ${ }^{4,5}$ Department of Physiology, Dow International Medical College, Dow University of Health Sciences, Karachi, \\ Pakistan.
}

\begin{abstract}
To determine difference in the perceptions and preferences of medical and non-medical students about utilization of different teaching methods. White Board, Overhead Projector, PowerPoint presentations, Computer Assisted (CD ROM's)/Web Based learning and Problem Based learning in order to recommend ways for their optimal utilization.

Methods: Cross sectional survey was conducted on a convenient sample of 1173 undergraduate students belonging to medical and non-medical colleges from May 2011 to September 2011. The total response rate was $90.23 \%$.

Results: Over all $30.2 \%$ of the students chose PBL to be a reliable mode of teaching and $32.4 \%$ believed that it provides a better learning experience. Majority of the students (34.8\%, $43.5 \%$ and $40.8 \%)$ preferred case studies over PBL, Lectures, role playing and video tapes and believed that case studies develops the ability to understand the topic better and it is an interesting and interactive teaching method respectively. Majority of the medical students chose PBL whereas the non-medical students preferred case studies to be the best teaching method.
\end{abstract}

Conclusion: Students have chosen PBL and case studies as the best teaching method and have preferred the integration of different teaching methods for better understanding.

Keywords: Teaching methods, Lectures, role playing, videotapes, problem based learning, case studies.

\section{Introduction:}

There has been a growing interest over the past decade for a paradigm shift from teacher-centered mode of delivery to student-centered. It has been emphasized that such a shift can help for providing a contextually meaningful framework so that core knowledge is delivered with sound concepts of the subject ${ }^{[1]}$. A number of teaching methods are employed at the undergraduate level to appeal to students with different learning styles. It includes didactic lectures, role playing, case studies, demonstrations through videotapes, problem based learning (PBL) and several others to address specific learning styles of students by providing them contextual opportunities ${ }^{[2]}$.

All the different learning strategies are designed keeping in mind the preference of learners' and to attract their active participation; an adopted example is of models and video demonstrations for the visual learners, active discussion for auditory learners, models and role-playing for kinesthetic and tactile learners ${ }^{[3]}$. Presentation of the material in a variety of ways and format also attracts the active participation of the students, which enhance their understanding and learning of the subject ${ }^{[4,5]}$. Nowadays, availability of several teaching aids like White Board, Overhead Projector, Multimedia, PowerPoint, Computer Assisted (CD ROMs) and Web based learning have facilitated and assisted the academics in their teaching.

The studies done in west to show effectiveness of various learning strategies has shown little documentary evidence, which appears to be the hindrance in adopting these strategies ${ }^{[3]}$. The faculty members must have thorough knowledge of the subject matter along with awareness of the learners' characteristics and learning styles preferences to be effective ${ }^{\left[{ }^{[6]}\right.}$. Most of the faculty members have an up to date knowledge of their subject of specialization. However, understanding the differences in learning style preferences of the learner is very important but an underutilized approach to improve understanding of the learners'.

Learning can be through cognitive, affective and psychomotor domains. Students have shown to grasp new knowledge by the help of visual, auditory and tactile sensory modalities ${ }^{[7]}$. The mode of delivery and transfer of information in a lecture appeals particularly to those with strong verbal/linguistic skills. Role playing, case studies and PBL tend to accommodate those with strong visual/spatial intelligence also ${ }^{[8]}$. Role playing and case studies can be interactive or non-interactive depending upon the size of the group as compared to PBL 
which is usually interactive and involves small group discussions. All these teaching tools have some advantages and disadvantages.

The study was designed to determine the perception and preferences of the undergraduate students' about the use of contemporary teaching methods in a class room so that they can be utilized in an effective and efficient manner for comprehensive delivery of the content and to develop better understanding of the subject matter.

\section{Methodology:}

A comparative cross sectional survey was conducted from May 2011 to September 2011 on a convenient sample of 1100 undergraduate students belonging to different specialties like medicine, pharmacy, nursing, engineering and management. The students were broadly divided into two categories; medical and nonmedical. Out of 1300 questionnaires administered, 1191 were returned and 18 were incomplete and therefore, were not included in the analysis. The total response rate was $90.23 \%$. The students were asked to fill a questionnaire during their leisure time after explaining the purpose of the study and taking informed consent.

The study questionnaire was designed carefully after literature review and some of the questions were adapted from similar previous studies ${ }^{[9]}$. It was pre-tested on a sample of 25 participants. Any ambiguities in the questions or responses were removed before its implementation. The questionnaire had two sections. The first section assessed the age and class profile of the students while the second one assessed the preference of the students among different teaching methods in terms of developing interest and interaction, increasing understandability and provision of a better learning experience.

Statistical Package for the Social Sciences (SPSS version 17.0) was used to analyze the data using descriptive statistics to evaluate the frequency distribution and percentages. The mean significant differences and $p$ values were calculated using the Mann-Whitney test.

The study was approved from the principals of all the universities involved in the study. An informed consent was obtained from every student and confidentiality was assured.

\section{Results:}

Of the 1173 students that responded, $635(54.1 \%)$ were males and $538(45.9 \%)$ were females. These students were classified into two groups; medical or non-medical on the basis of the discipline they are seeking their higher education in. 612 (52.2\%) students were studying medical related fields while 561 (47.8\%) students were studying engineering or management sciences. The mean age of the students who participated in the study was $21.30 \pm 1.92$ years.

\begin{tabular}{|c|c|c|c|c|c|c|}
\hline & \multicolumn{5}{|c|}{ Which method is reliable type } & \multirow[b]{2}{*}{$p$} \\
\hline & $\begin{array}{l}\text { Lectures* } \\
(\%)\end{array}$ & $\begin{array}{c}\text { Role } \\
\text { playing§ } \\
(\%)\end{array}$ & $\begin{array}{c}\text { Case } \\
\text { studies } \\
(\%)\end{array}$ & $\begin{array}{c}\text { Video tapes } \\
(\%)\end{array}$ & PBL $^{\square}(\%)$ & \\
\hline Non Medical & $25(4.1)$ & $120(19.6)$ & $272(44.4)$ & $81(13.2)$ & $114(18.6)$ & \multirow{3}{*}{$<0.001$} \\
\hline Medical & $46(8.2)$ & $112(20.0)$ & $54(9.6)$ & $109(19.4)$ & $240(42.8)$ & \\
\hline \multirow[t]{2}{*}{ Total } & $71(6.1)$ & $232(19.8)$ & $326(27.8)$ & $190(16.2)$ & $354(30.2)$ & \\
\hline & \multicolumn{6}{|c|}{ Develops the ability to understand the topic better } \\
\hline Non Medical & $85(13.9)$ & $98(16.0)$ & $323(52.8)$ & $25(4.1)$ & $81(13.2)$ & \multirow{3}{*}{$<0.001$} \\
\hline Medical & $76(13.5)$ & $72(12.8)$ & $187(33.3)$ & $32(5.7)$ & $194(34.6)$ & \\
\hline \multirow[t]{2}{*}{ Total } & $161(13.7)$ & $170(14.5)$ & $510(43.5)$ & $57(4.9)$ & $275(23.4)$ & \\
\hline & \multicolumn{6}{|c|}{ Provides better learning experience } \\
\hline Non Medical & $116(19.0)$ & $75(12.3)$ & $239(39.1)$ & $57(9.3)$ & $125(20.4)$ & \multirow{3}{*}{$<0.001$} \\
\hline Medical & $73(13.0)$ & $75(13.4)$ & $100(17.8)$ & $58(10.3)$ & $255(45.5)$ & \\
\hline \multirow[t]{2}{*}{ Total } & $189(16.1)$ & $150(12.8)$ & $339(28.9)$ & $115(9.8)$ & $380(32.4)$ & \\
\hline & \multicolumn{6}{|c|}{ I prefer to... } \\
\hline Non Medical & $80(13.1)$ & $92(15.0)$ & $231(37.7)$ & $66(10.8)$ & $143(23.4)$ & \multirow{3}{*}{$<0.001$} \\
\hline Medical & $67(11.9)$ & $68(12.1)$ & 177 (31.6) & $45(8.0)$ & $204(36.4)$ & \\
\hline \multirow[t]{2}{*}{ Total } & $147(12.5)$ & $160(13.6)$ & $408(34.8)$ & $111(9.5)$ & 347 (29.6) & \\
\hline & \multicolumn{6}{|c|}{ More interesting and interactive teaching method } \\
\hline
\end{tabular}




\begin{tabular}{|l|l|l|l|l|l|l|}
\hline Non Medical & $92(15.0)$ & $86(14.1)$ & $297(48.5)$ & $50(8.2)$ & $87(14.2)$ & \\
\cline { 1 - 6 } Medical & $85(15.2)$ & $66(11.8)$ & $181(32.3)$ & $33(5.9)$ & $196(34.9)$ & \multirow{2}{*}{0.001} \\
\cline { 1 - 6 } Total & $177(15.1)$ & $152(13.0)$ & $478(40.8)$ & $83(7.1)$ & $283(24.1)$ & \\
\hline
\end{tabular}

* Lectures, § Role Playing, $\propto$ Case studies, $\square$ Videotapes, $\square$ Problem based Learning

$\square p<0.05=$ significant, $p<0.01=$ vey significant, $p<0.001=$ highly significant

Table 1: The perception and preferences of the undergraduate students' towards different teaching methods

Majority $(42.8 \%)$ of the medical students chose PBL as a reliable teaching method whereas around (44.4\%) of the non-medical students chose case studies to be the reliable teaching method. Very little difference was observed in PBL (34.6\%) and case studies (33.3\%) when development of ability to understand the topic better was asked from medical students while non-medical students supported case studies (52.8\%). Similar trend was seen when asked about the method that provides the better learning experience with medical students considering PBL (45.5\%) whereas non-medical students favored case studies (39.1\%). The medical students preferred PBL (36.4\%) while non-medical students preferred case studies (37.7\%). The similar observation was observed with respect to the teaching method which is more interesting and interactive as medical students chose PBL (34.9\%) and non-medical students (48.5\%) chose case studies. (Table 1)

\begin{tabular}{|l|l|l|}
\hline \multicolumn{1}{|c|}{ Questions } & \multicolumn{1}{|c|}{$\begin{array}{c}\text { Non-medical } \\
\mathbf{n}(\%)\end{array}$} & $\begin{array}{c}\text { Medical } \\
\mathbf{n}(\%)\end{array}$ \\
\hline $\begin{array}{l}\text { Integration of multimedia/PowerPoint presentations teaching with } \\
\text { AVA/ WB in a lecture }\end{array}$ & $882(75.2)$ & $973(82.9)$ \\
\hline $\begin{array}{l}\text { Difficulties in switching from one visual aid to other in short } \\
\text { duration }\end{array}$ & $203(17.3)$ & $171(14.5)$ \\
\hline $\begin{array}{l}\text { Difficulties in using two or more methods simultaneously by the } \\
\text { teacher }\end{array}$ & $163(13.9)$ & $189(16.1)$ \\
\hline $\begin{array}{l}\text { Student-centered interactive sessions are more helpful in } \\
\text { developing the concepts }\end{array}$ & $965(82.3)$ & $992(84.5)$ \\
\hline $\begin{array}{l}\text { Lectures by local/foreign scholars by video conferencing as a } \\
\text { future teaching method in universities }\end{array}$ & $1044(89.0)$ & $978(83.3)$ \\
\hline Handouts of topic/lecture be provided & $834(71.1)$ & $921(78.5)$ \\
\hline $\begin{array}{l}\text { Provision of the handouts reducing the need of getting detailed } \\
\text { knowledge from book }\end{array}$ & $657(56.0)$ & $827(70.5)$ \\
\hline
\end{tabular}

Table-2: Generalized attitude of the students towards different teaching aids.

Table- 2 shows generalized attitude of the students towards different teaching aids. $75.2 \%$ non-medical and $82.9 \%$ medical students preferred teaching using combination of PowerPoint presentations with the AVA or WB. $82.3 \%$ non-medical students and $85.5 \%$ medical students did not feel any difficulty in switching from one mode of teaching to other during the delivery of lecture. $86.1 \%$ non-medical and $83.9 \%$ medical students did not feel any difficulty when two or more teaching aids were used simultaneously. Majority of non-medical (82.3\%) and medical (84.5\%) students favored student centered approach in understanding the concepts. $89 \%$ nonmedical students and $83.3 \%$ medical students agreed that lectures by foreign scholars can be used a teaching tool in future. $71.1 \%$ non-medical and $78.5 \%$ medical students wanted a handout to be provided after a lecture and $56 \%$ non-medical and $70.6 \%$ medical students considered that provision of the handouts reduces the need of getting detailed knowledge from the textbook.

\section{Discussion:}

Although students need to memorize a number of facts but developing concepts is fundamental to the understanding of medical sciences. Students develop concepts and acquire facts through lectures and textbooks. Several different teaching methodologies can be employed; each has its advantages and disadvantages. ${ }^{[10]}$ Lecture is used to deliver information to larger masses but it is usually a one-way communication and involves minimal engagement of the students ${ }^{[11]}$. It takes active involvement of the student with the subject matter to develop understanding that is mostly not achieved in the lecture halls ${ }^{[12]}$.

Several studies have shown that students consider video based demonstrations as an effective learning tool ${ }^{[13,14]}$ Video conferencing and video streaming have proved its effectiveness in delivering lectures to off campus students. Those who have missed their lectures can also stream the video online to get maximum benefit 
from this technology. Similar results were found in our study. $89 \%$ students agreed that online lectures through video conferencing could play a promising role in higher education.

The modern teaching is shifting from teacher centered to students centered education, which has led to a shift in the role of the teachers as well. The primary objective of the teachers' is to involve students in an active learning process ${ }^{[15]}$. The role of Problem Based Learning in actively involving the students in learning process is identified in several studies ${ }^{[16,17]}$. Problem Based Learning (PBL) has largely replaced formal teaching method and has become a popular approach to learning in medical curricula worldwide. It is an active learning process, which uses hypothetical medical case scenarios as the basis for learning. Discussion helps students identify the learning issues necessary to understand the case scenarios and leads them to seek information through individual, self-directed study ${ }^{[12]}$. Another study conducted in India attempted using the PBL along with the didactic lectures and proved its effectiveness in creating motivation in students to do self directed learning. ${ }^{[18]}$

The difference in approach of the medical and non-medical students which is clearly evident in our study can be explained by the nature of the subjects that they have to deal with during their studies. Both case studies and PBL involves active participation of the learners by involving them. Medical practice is essentially a problem-solving activity whether at individual, family, or community levels. ${ }^{[19]}$ PBL was opted by the majority of medical students as it emanates from a clinically based problem. It encourages independent learning and deeper understanding of a particular topic and integration of other related fields in an attempt to correlate the findings to establish a proper diagnosis and then treatment. Non-medical students, on the other hand, preferred case studies as it gives them an opportunity to build upon their knowledge on the prior experiences of the experts in the field. These experiences will help them in decision making if any of such situation appears again like in management sciences or in business studies. Case studies are also useful for medical students but as medicine is an ever changing science and the presentation of the patients can be very different, these case studies does add up to the knowledge but doesn't help in the development of problem-solving skills

Studies show that students have achieved higher scores in undergraduate courses when teaching style was designed according to their learning style preferences ${ }^{[20]}$. Rochford ${ }^{[21]}$ found significantly higher achievement when instruction material was prepared in response to learning style at an urban community college. Miller ${ }^{[22]}$ observed a significant improvement in examination scores as well as in students' attitude towards learning when information delivery style matched students' learning styles. Our findings do not correlate with the findings of Slater and Lujan ${ }^{[23]}$ who found gender specific learning style preferences among undergraduate students. Our results showed that there was no significant difference in learning style preference of male and female students.

\section{Conclusion:}

The teaching paradigm has shifted from traditional teacher centered mode of delivery to student centered delivery of the contents. Students retain minimal information obtained from traditional didactic teaching and have difficulty transferring knowledge to new experiences. Both the methods chosen by the students help them identify, analyze, and resolve learning issues using knowledge from previous experiences and learning, not relying solely on recall. Faculty members will also be able to use this information to develop better understanding of the subject matter in students by taking in to consideration their preferred method of teaching. It will also facilitate them in developing interest and active participation of students in the classroom.

\section{References:}

[1] Barr RB, Tagg J. A new paradigm for undergraduate education. Change. 1995;27(6):13-25.

[2] Ramsden P. Learning to teach in higher education. London, Routledge: Psychology Press 1992.

[3] Rao SP, DiCarlo SE. Active learning of respiratory physiology improves performance on respiratory physiology examinations. Adv Physiol Educ. 2001;25:127-133.

[4] Grinder M. Riding the Information Conveyor Belt. Portland, OR: Metamorphus, 1991.

[5] Tennyson RD. An instructional strategy planning model to improve learning and cognition. Computers in Human Behavior. 1988;4:13-22.

[6] Gudmundsdottir S, Shulman L. Pedagogical content knowledge in social studies. Scand J Educ Res. 1987;31:59-70.

[7] Fleming N.D. I am different: not dumb: modes of presentation (VARK) in the tertiary classroom. In: Research and development in higher education, edited by Zelmer A, Canberra, Australia's: Proceedings of the 1995 Annual conference of the higher education and research development society of Australia 1995:303-18.

[8] Reese AC. Implications of results from cognitive science research for medical education. Educ online (Serialonline). $1998 ; 3: 1$. http://www.utmb.edu/meo/

[9] Chaudhary R, Dullo P, Gupta U. Attitude of 1st MBBS medical students about two different visual aids in physiology lectures. Pak J Physiol, 2009; 5(2), 16-19.

[10] McKeachie WJ. Teaching tips: A guidebook for the beginning college teacher. 7th ed. Lexington, MA, US: DC Heath 1978.

[11] Svinicki MD. A comparison of some alternative teaching modes. Alternative Teaching Methods, Section 4, University of Texas at Austin

[12] http://www.utexas.edu/academic/etc/sourcebook/medical.html

[13] Shefton A. International workshop: modern approaches to teaching and learning physiology. Advan Physiol Educ. 2001;25:64-71. 
[14] Hecht J, Klass, P. The evaluation of qualitative and quantitative research classes when delivered via distance education. Paper presented at the Annual Meeting of the American Educational Research Association. Montreal, Canada, April 19-23, 1999

[15] Ivers K, Baron A. Teaching telecommunications: A comparison between video and computer based instruction. Educational Resource Information Center, (ERIC) ED 378 963. from the angle of assessment. Review of Educational Research, 1994; 75(1), 2761 .

[16] Kumar S, An innovative method to enhance interaction during lecture sessions. Adv Physiol Educ. 2003; $27: 20-25$.

[17] Ochoa T, Robinson J. Revisiting group consensus: Collaborative learning dynamics during a problem-based learning activity in education. Teacher Education and Special Education. 2005;28(1):10-20.

[18] Gijbels, D., Dochy, F., Van den Bossche, P., \& Segers, M. Effects of problem-based learning: A meta-analysis 2005

[19] Ghosh S. Combination of didactic lectures and case-oriented problem-solving tutorials toward better learning: perceptions of students from a conventional medical curriculum. Adv Physiol Educ. 2007;31:193-197.

[20] Hamad B. Problem based education in Gezira, Sudan. Med Educ. 1985;19:357-363.

[21] Mangino C, Griggs S. Learning styles in higher education. In: Synthesis of the Dunn and Dunn Learning styles model Research: Who, What, When, Where and so what - the Dunn and Dunn Learning styles models and its Theoretical Corn stone, edited by Dunn R, Griggs S. New York, St. John's University 2003.

[22] Rochford R. Improving academic performance and retention among remedial students. Community College Enterpr. 2004; 10:2336.

[23] Miller JA. Enhancement of achievement and attitude through individualized learning-style presentation of two allied health courses. J Allied Health. 1998;27:150-6.

[24] Slater JA, Lujan H. Does gender influence learning style preference of first year medical students. Advan Physiol Educ. 2007;31:336-42. 